\title{
Impact of beef cattle grazing systems on treading damage and forage supply
}

\author{
G.W. SHEATH and C.J. BOOM \\ AgResearch, Ruakura Research Centre, PB 3123, Hamilton, New Zealand
}

\begin{abstract}
Levels of treading damage were measured for a range of cattle feeding regimes and grazing managements which were compared during winter and spring. These paddock- and systems-based results provide a context within which component research on soil and plants can be interpreted. Soil surface damage was higher in farmlets with heavier cattle (390 kg vs. $200 \mathrm{~kg}$ steers) and on paddocks where feeding was restricted through the use of a slow rotation (100-120 days vs. 35-45 days). Where cattle grazed under wet conditions, with a pre- and post- grazing herbage mass of 2400 and $650 \mathrm{~kg} \mathrm{DM} /$ ha respectively, damage levels reached $60-70 \%$ of the soil surface. Under these conditions, $300-350 \mathrm{~kg} \mathrm{DM} / \mathrm{ha}$ of initial forage on offer was pushed onto or into the surface soil; and pasture growth rates during early-mid spring would be reduced by $10 \mathrm{~kg} \mathrm{DM} / \mathrm{ha} /$ day. In practice the objective of grazing plans and management should be to minimise these negative impacts within the constraints of the required feeding regimes. Recommendations are made for the alignment of stock class and enterprise with land capabilities and the feed allocation processes of a winter rotation.
\end{abstract}

Keywords: cattle grazing systems, forage supply treading damage

\section{Introduction}

As a consequence of market forces, greater numbers of heavier cattle are being finished on North Island hill country farms. This means that a greater area and range of soils are being exposed to the potential damage of soil and pasture as a result of treading. Short-term losses in pasture density and production can occur; and surface soil damage provides the potential for sedimentation of waterways (Sheath \& Carlson 1997; Nguyen et al. 1997). Longer-term effects on soil compaction (Greenwood \& McNamara 1992) and aquatic life (Quinn et al. 1994) are also possibilities.

Studies at Whatawhata Research Centre seek to determine the impact of treading processes on soil- water properties and forage supply. This paper reports on the levels of treading damage which occurred under a range of cattle feeding regimes and grazing managements during winter and spring. The results provide a context within which component research on soil and plants can be interpreted. Several practical planning and management recommendations are made with the view of minimising any negative impacts.

\section{Methods}

\section{Farm systems compensation (Experiment 1)}

A farm systems experiment was run for 2 years, studying the effects of two different winter management systems on cattle performance (e.g., liveweight gain) and soil treading damage. This paper deals only with the treading damage issues.

The experiment consisted of a $2 \times 2$ factorial design with 2 replicates, giving a total of 8 self-contained farmlets. Treatments were either rising 1-year (R1-200 $\mathrm{kg}$ liveweight) or rising 2-year (R2-390 kg liveweight) Angus steers which were managed in a fast (FR) or a slow rotation (SR) during the winter period (early Maymid August). From mid August on, the SR treatments were allowed to consume any saved feed on their farmlets.

Each farmlet consisted of about $45 \%$ easy rolling contour and 55\% steep hill land with the R1 farmlets being 7.2 ha and the R2 farmlets 11.9 ha in area. Farmlets were stocked with 15 Angus steers and either 50 or 30 Romney ewes for the R1 and R2 farmlets, respectively. Cattle were run on separate blocks from the ewes through winter and spring. The steep hill soils could be broadly described as Waingaro steep soils, a northern yellowbrown earth derived from argillaceous greywacke (Bruce 1976). The easy contoured areas are a mix of yellowbrown earth (Kawa hill soils) and yellow-brown loam (Dunmore hill soils).

During late winter, all grazed paddocks were assessed for treading damage. This occurred over a 6week period in the first year of the study (16.7.93-20.8.93) and a 7-week period in the second year (8.7.94-24.8.94). At the completion of each grazing, paddock assessments of treading damage involved measurements at 100 points ( $2 \mathrm{~mm}$ diameter) along fixed transect lines. If present, visual treading 
damage (Sheath \& Carlson 1997) and bare ground was recorded at each point; and land class was categorised as either stock camp, easy contour $\left(<25^{\circ}\right)$ or steep contour $\left(>25^{\circ}\right)$.

During the first experimental year, rainfall was high until the beginning of the treading study (i.e., early July), but during the study conditions were relatively dry (Table1). Rainfall pattern in the second year was somewhat reversed, with high rainfall occurring during the study period (i.e., July-August).

\section{Controlled growth path (Experiment 2)}

During the winter and spring of 1995, an experiment was run to study nutrition and seasonal interactions in cattle performance. The design was a $3 \times 2$ factorial, with no replicates. Treatments were 3 pasture allowances (high, medium and low) by 2 sex/breed differences (Friesian bulls or Angus steers). All treatments were allocated 10 rising 2-year-old cattle. The experiment was broken into 2 periods of 8 weeks duration, viz winter (16 June-10 August) and spring (11 September6 November).

All land grazed within the experiment was of an easy contour (easy contoured soil type as described; $<15^{\circ}$ slope). Pre-graze pasture mass was similar between treatments and differing pasture residuals were used to generate the feeding allowances. Different paddock areas were allocated to each treatment in order to achieve these residuals. Grazing durations were 3-4 days (i.e., 2 shifts per week) for all treatments.

Damage level for each paddock was assessed as described for Experiment 1. Gravimetric soil moisture levels $(0-75 \mathrm{~mm})$ were also assessed for each paddock at the end of the grazing duration. Rainfall was $23 \%$ above the long-term average during both the winter and spring experiments (Table 1).
Table 1 Rainfall $(\mathrm{mm})$ for the relevant experimental months of 1993-1995 and the long-term site mean.

\begin{tabular}{lccccc}
\hline & June & July & August & September & October \\
\hline 1993 & 245 & 39 & 129 & 89 & 78 \\
1994 & 134 & 250 & 153 & 263 & 165 \\
1995 & 261 & 287 & 142 & 184 & 170 \\
Long-term mean & 176 & 175 & 160 & 136 & 137 \\
\hline
\end{tabular}

In order to estimate the amount of pasture which was buried during grazing, 36 quadrats $(0.32 \mathrm{~m} \times 0.26$ m) were marked out after grazing each week (6 per treatment) to cover the full range of damage levels. Plots were assessed for treading damage and then 8 soil cores $(45 \mathrm{~mm}$ diameter) were taken from each plot. Above-ground herbage was removed from the cores, and then cores were broken up and pasture leaf and pseudostem trodden onto and into the soil was removed, washed, dried and weighed. Linear regressions, which relate the effect of treading damage to the amount of herbage trodden onto and below the soil surface, were developed for the winter and spring experiments.

\section{Results}

\section{Experiment 1}

During the 6-week study period of the first year, the pre- and post-graze herbage mass for the SR treatments were $3100-3300 \mathrm{~kg} \mathrm{DM} / \mathrm{ha}$ and $700 \mathrm{~kg} \mathrm{DM} / \mathrm{ha}$ respectively (Table 2). Under these nutritional conditions approximately $30 \%$ of the cattle block was grazed and this represented an equivalent rotation length of 120 days. Where cattle were moved more rapidly in the FR farmlets (i.e., 45-day rotation length), $80-90 \%$ of the paddocks in the cattle blocks were grazed. The pre- and post-grazing combinations for the FR farmlets were $2300-2500 \mathrm{~kg} \mathrm{DM} / \mathrm{ha}$ and $1000-1200 \mathrm{~kg} \mathrm{DM} / \mathrm{ha}$, respectively.

Table 2 Grazing conditions in Experiment 1 and the resultant levels of treading damage and bare ground.

\begin{tabular}{|c|c|c|c|c|c|c|c|c|}
\hline $\begin{array}{l}\text { Stock class } \\
\text { and rotation } \\
\text { speed }\end{array}$ & $\begin{array}{c}\text { Steer } \\
\text { liveweight } \\
(\mathrm{kg})\end{array}$ & $\begin{array}{c}\text { Land area } \\
\text { grazed } \\
(\%)\end{array}$ & $\begin{array}{l}\text { Grazing } \\
\text { rotation } \\
\text { length } \\
\text { (days) }\end{array}$ & $\begin{array}{c}\text { Pre-graze } \\
\text { herbage } \\
\text { mass } \\
\text { (kg DM/ha) }\end{array}$ & $\begin{array}{c}\text { Post-graze } \\
\text { herbage } \\
\text { mass } \\
\text { (kg DM/ha) }\end{array}$ & $\begin{array}{c}\text { Steep } \\
\text { land } \\
\text { trodden } \\
(\%)\end{array}$ & $\begin{array}{l}\text { Treading } \\
\text { damage } \\
(\% \text { and } \mathrm{SE})\end{array}$ & $\begin{array}{c}\text { Bare } \\
\text { ground } \\
(\% \text { and } S E)\end{array}$ \\
\hline \multicolumn{9}{|l|}{1993} \\
\hline $\mathrm{R} 1, \mathrm{FR}$ & 212 & 97 & 45 & 2547 & 1183 & 12.4 & $34.2 \pm 1.7$ & $13.1 \pm 1.6$ \\
\hline $\mathrm{R} 1, \mathrm{SR}$ & 198 & 33 & 123 & 3175 & 682 & 9.4 & $35.0 \pm 2.7$ & $26.4 \pm 3.2$ \\
\hline $\mathrm{R} 2, \mathrm{FR}$ & 406 & 79 & 46 & 2367 & 994 & 10.5 & $39.0 \pm 1.8$ & $19.5 \pm 1.9$ \\
\hline $\mathrm{R} 2, \mathrm{SR}$ & 377 & 27 & 115 & 3306 & 699 & 9.1 & $54.6 \pm 1.5$ & $36.1 \pm 3.5$ \\
\hline \multicolumn{9}{|l|}{1994} \\
\hline $\mathrm{R} 1, \mathrm{FR}$ & 208 & 130 & 37 & 1912 & 1118 & 24.6 & $17.9 \pm 1.4$ & $12.4 \pm 1.2$ \\
\hline $\mathrm{R} 1, \mathrm{SR}$ & 197 & 38 & 103 & 2410 & 823 & 17.6 & $36.0 \pm 2.8$ & $22.4 \pm 2.5$ \\
\hline $\mathrm{R} 2, \mathrm{FR}$ & 366 & 134 & 40 & 2150 & 1155 & 18.4 & $21.3 \pm 1.5$ & $10.9 \pm 1.2$ \\
\hline $\mathrm{R} 2, \mathrm{SR}$ & 338 & 40 & 99 & 2630 & 758 & 18.3 & $46.0 \pm 3.1$ & $24.3 \pm 2.8$ \\
\hline
\end{tabular}


Where cattle were grazing to lower residuals in the SR treatments, higher levels of bare ground were recorded. Only in the R2 farmlets was this reflected in higher soil surface damage levels. Within the R1 treatments, damage levels were similar. The heavier R2 steers $(\approx 390 \mathrm{~kg})$ caused more damage and bare ground than the R1 steers $(\approx 200 \mathrm{~kg})$ when comparisons are made within their rotation treatments.

During the 7-week study period of the second year, post-grazing levels were managed to achieve a similar outcome to the first year. However, all pre-graze levels were lower and consequently all treatments moved more rapidly (i.e., shorter rotation length). For the SR farmlets $40 \%$ of the paddocks were grazed, whereas all paddocks in the FR farmlets were grazed at least once. As in the first year, the grazed paddocks of SR farmlets had greater levels of damage and more bare ground. Similarly, the heavier R2 cattle caused more soil surface damage.

A more detailed description of the average damage levels recorded for each week of both study years are given in Figures 1 and 2. During winter 1993, the significant feature was the similarity in damage pattern between the R1, SR cattle and the two FR farmlets. During winter 1994, a similar situation occurred until the week of 26 July. Thereafter, soils were wetter, damage levels were higher and the R1, SR farmlets recorded similar damage to their older and heavier counterparts.

\section{Experiment 2}

This experiment sought to compare the nutritional responses of R2, Friesian bulls and Angus steers during winter and spring and concurrently provided the opportunity to measure treading impacts associated with these treatments. Because there were no significant differences in treading damage between bulls and steers, data are averaged for the three nutritional treatments across these two stock classes (Table 3).
Figure 1 Treading damage (\% soil surface) during winter 1993 of Experiment 1.

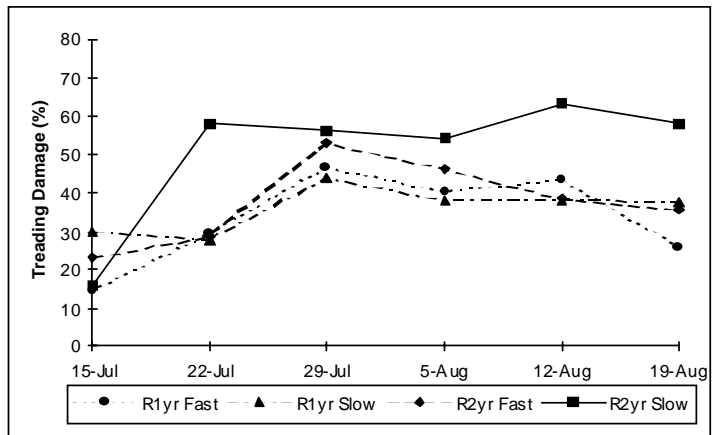

Figure 2 Treading damage (\% soil surface) during winter 1994 of Experiment 1.

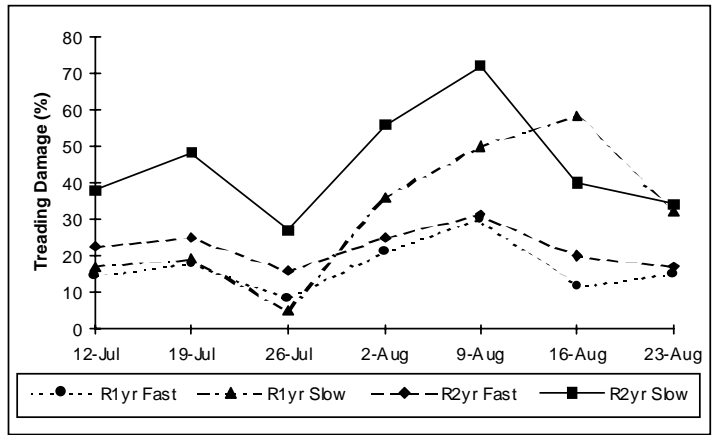

For both winter and spring, pre-grazing herbage mass was managed to similar levels of $2400 \mathrm{~kg} \mathrm{DM} / \mathrm{ha}$. To generate the nutritional differences, residual grazing levels ranged from 600 to $1400 \mathrm{~kg} \mathrm{DM} / \mathrm{ha}$ in winter and 700 to $1600 \mathrm{~kg} \mathrm{DM}$ in spring. The low residual/ allowance treatments were therefore similar to the R2, SR farmlets of the previous experiment; and the high residual/allowance more closely represented the R2, FR

Table 3 Grazing conditions in Experiment 2 and the resultant levels of treading damage and lost herbage.

\begin{tabular}{|c|c|c|c|c|c|c|}
\hline & $\begin{array}{c}\text { Steer } \\
\text { liveweight } \\
(\mathrm{kg})\end{array}$ & $\begin{array}{l}\text { Total area } \\
\text { grazed } \\
\text { (ha) }\end{array}$ & $\begin{array}{c}\text { Pre-graze } \\
\text { herbage mass } \\
(\mathrm{kg} \mathrm{DM} / \mathrm{ha})\end{array}$ & $\begin{array}{c}\text { Post-graze } \\
\text { herbage mass } \\
\text { (kg DM/ha) }\end{array}$ & $\begin{array}{c}\text { Treading } \\
\text { damage } \\
(\%)\end{array}$ & $\begin{array}{c}\text { Trodden } \\
\text { pasture } \\
(\mathrm{kgDM} / \mathrm{ha})\end{array}$ \\
\hline \multicolumn{7}{|l|}{ Winter } \\
\hline High allowance & 441 & 13.09 & 2458 & 1394 & 39.3 & 240 \\
\hline Medium allowance & 424 & 8.58 & 2407 & 987 & 53.5 & 300 \\
\hline $\begin{array}{l}\text { Low allowance } \\
\text { SED }\end{array}$ & 408 & 5.76 & 2379 & 647 & $\begin{array}{l}64.3 \\
2.05\end{array}$ & 346 \\
\hline \multicolumn{7}{|l|}{ Spring } \\
\hline High allowance & 533 & 14.07 & 2468 & 1599 & 23.0 & 196 \\
\hline Medium allowance & 511 & 8.76 & 2473 & 1162 & 30.7 & 235 \\
\hline Low allowance & 472 & 5.57 & 2451 & 728 & 36.6 & 265 \\
\hline SED & & & & & 3.2 & \\
\hline
\end{tabular}


farmlets during winter. Cattle were heavier in this experiment and, combined with wet soil conditions (Figure 3), overall treading levels were higher in winter compared with Experiment 1.

As grazing residuals were reduced, the levels of soil surface damage increased. Where nutritional allowance was lowest, an average of $64 \%$ of the soil surface was damaged in paddocks grazed during the winter. Under drier soil conditions in spring, treading damage levels were approximately half those of the corresponding winter treatments.

Figure 3 provides greater detail on rainfall, soil moisture and the resultant, damage levels during winter 1995. Throughout the study period, soil moisture levels were high, sometimes exceeding the plastic limit (72\% oven dry weight) for this soil type. Under these controlled experimental conditions, levels of treading damage remained relatively consistent within treatments.

While soil moistures were at or below $70 \%$ during spring (Figure 4), the treading damage was low and treatment differences were not great. Only during a wet 2-3-week period, when soil moisture approached the plastic limit, did damage levels match those during the winter in terms of both absolute level and treatment relativity.

Within this experiment, the amount of herbage trodden onto and below the soil surface was estimated. The linear regressions that relate trodden herbage $(\mathrm{H}-$ $\mathrm{kg} \mathrm{DM} / \mathrm{ha}$ ) to levels of soil surface damage (D-\%) are:

$$
\begin{aligned}
& \text { Winter } \mathrm{H}=4.23 \mathrm{D}+74\left(\mathrm{r}^{2}=0.33 * *\right) \\
& \text { Spring } \mathrm{H}=5.11 \mathrm{D}+78\left(\mathrm{r}^{2}=0.51^{* *}\right)
\end{aligned}
$$

In translating these relationships into the context of Experiment 2, this suggests that the average amount of trodden herbage for a single grazing, ranged from 240 to $340 \mathrm{~kg} \mathrm{DM} / \mathrm{ha}$ during winter and 200 to $260 \mathrm{~kg} \mathrm{DM} /$ ha during spring (Table 3 ).

\section{Discussion}

The general treatment effects are consistent with expectations, in that managements involving heavier cattle and/or lower grazing residuals resulted in greater treading damage. More significant to this discussion are the implications of these damage levels for forage availability and resource status.

The immediate effect of treading is reduced herbage utilisation. In these experiments, treatments which mimic a slow rotation and aim to maintain cattle live-weight, resulted in visual damage to $45-65 \%$ of the soil surface during winter (R2 cattle). At the upper level, this would represent a loss of $350 \mathrm{~kg} \mathrm{DM} / \mathrm{ha}$ of pre-graze allocation. With targets of pre- and post-graze combinations of
Figure 3 Treading damage (\% soil surface), soil moisture $(\%)$ and rainfall (mm over 3.5 days) during winter 1995 in Experiment 2.
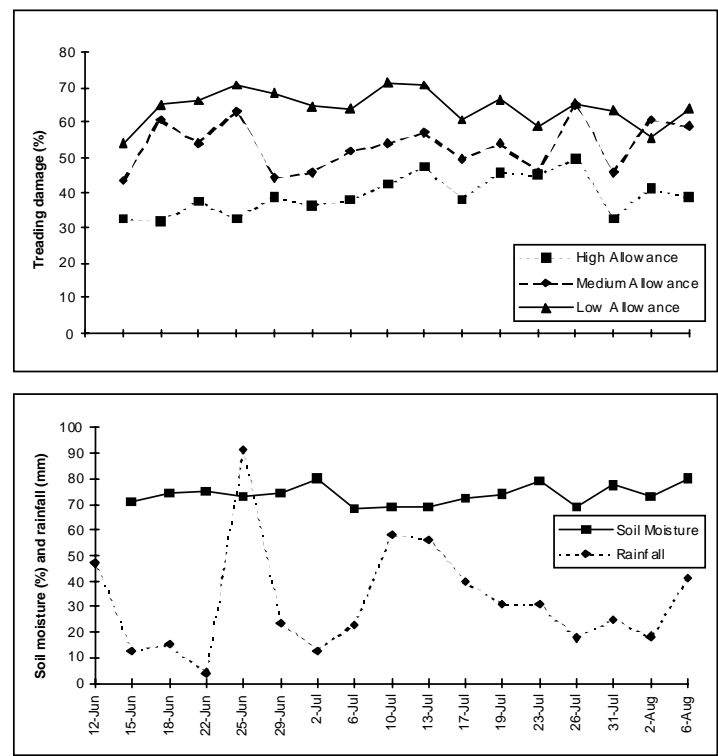

Figure 4 Treading damage (\% soil surface), soil moisture $(\%)$ and rainfall (mm over 3.5 days) during spring 1995 in Experiment 2.
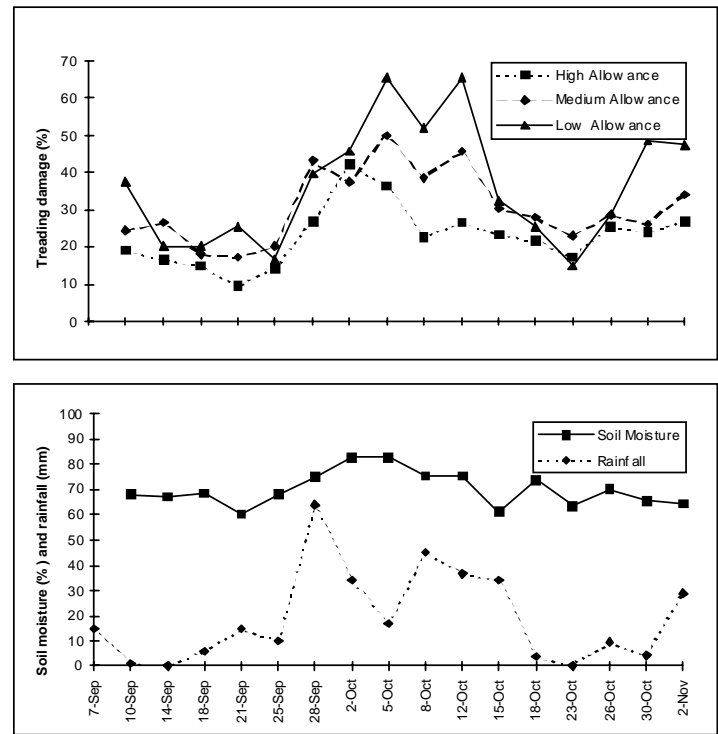

2500 and $700 \mathrm{~kg} \mathrm{DM} / \mathrm{ha}$ herbage mass respectively, this would represent a $20 \%$ wastage of available feed. The consequence would be underfeeding relative to budgeted targets. From a feed allocation perspective, it is also worth noting that even under high feeding regimes 
(i.e., high residuals, fast rotations) herbage losses owing to treading are in the vicinity of $150-200 \mathrm{~kg} \mathrm{DM} / \mathrm{ha}$ for heavier R2 cattle, and 100-150 kg DM/ha for lighter $\mathrm{R} 1$ cattle.

It could be argued that by reducing grazing intensity (i.e., faster stock rotation) the impact of treading will be lessened. However, there are several important consequences arising from reducing grazing duration and/or stock density. Feed rationing power is reduced and, therefore, the probability of a late winter-early spring feed deficit is higher. Further, if more rapid movement of herds lead to paddocks being grazed $2+$ times during the winter, then:

- feed levels will be lower for the second time around and animals will be more mobile as they search for feed;

- the accumulated forage losses and damage levels from two grazings is just as likely to be the same or higher than from a single grazing.

Single treading events during winter can also have carry-over effects for spring pasture growth rate. The results of Sheath \& Carlson (1997) would suggest that at least during the early spring period of AugustSeptember, pasture growth rates would be reduced by $10 \mathrm{~kg} \mathrm{DM} / \mathrm{ha} /$ day where damage was $60 \%$ of the soil surface area. This is a particularly significant reduction for mixed livestock pastures where average growth rates for these months may be only $25-30 \mathrm{~kg} \mathrm{DM} / \mathrm{ha} /$ day. Even more important, it is occurring at a time when both sheep and cattle enterprises are most sensitive to nutritional changes (Sheath et al. 1987).

The data from these experiments can give only an indication of likely effects arising from single grazing events. However, it is known that a predominance of cattle grazing over several ( $3+$ ) years can lead to changes in pasture composition and reductions in total annual herbage production (Lambert et al. 1985). Such a grazing system can also lead to high soil losses and sedimentation of wetlands and waterways (Lambert et al. 1985). Extrapolating the results of Sheath \& Carlson (1997) for easy-contoured ash soils, a range of soil surface damage levels of $30-60 \%$ would lead to sediment losses of $4-20 \mathrm{~g} / \mathrm{m}^{2}$ if rainfall and soil moisture conditions were such that surface runoff of water occurred.

In farming cattle through a winter, the reality is that some treading damage will occur. The challenge is to minimise this damage. For instance, heavier cattle certainly create greater levels of damage; therefore a general objective of the cattle finishing enterprise would be to design and achieve growth paths which ensure animals are marketed before their second winter, i.e., as rising 2-year-old cattle. In addition, a knowledge of the soil's robustness to treading would be of great assistance. This is indicated by the soil moisture plastic limits which tend to be greater on volcanic ash-derived soils than sedimentary- and alluvial-based soils. Heavier cattle can be concentrated on these more robust soils when moisture levels approach their plastic limits. This of course highlights the benefits of monitoring soil moisture levels. The current work of AgResearch at Ballantrae (Betteridge et al. 1997) will lead to good management guidelines in this respect.

Given the above, it would seem sensible to manage cattle in a way that damage is concentrated on a small area so that remedial action can follow. This may involve reseeding at the end of a break, and then continuous grazing by sheep over the spring. More rapid recovery of pasture cover is encouraged by this type of spring management (Sheath \& Carlson 1997). With this approach, it would be prudent to separate heavily damaged areas from waterways by a grazed riparian strip; and ensure that no surface water channels flow through the damaged area and directly into a waterway. The objective should be to confine any negative effects to the farm itself.

\section{REFERENCES}

Betteridge K.; Mackay, A.; Barker, D.J.; Shepherd, G.; Budding, P.J. 1997. Effect of cattle and sheep treading on sedimentary hill soil. 1. Surface soil configuration. Australian journal of soil research 35: in press.

Bruce, J.D. 1976. Soil map of part of Raglan Country, South Auckland, New Zealand. New Zealand Soil Bureau bulletin 41 .

Greenwood, P.B.; McNamara, R.M. 1992. An analysis of the physical condition of two intensively grazed Southland soils. Proceedings of the New Zealand Grassland Association 54: 71-75.

Lambert, M.G.; Devantier, D.P.; Nes, P.; Penny, P.E. 1985. Losses of nitrogen, phosphorus, and sediment in runoff from hill country under different fertiliser and grazing regimes. New Zealand journal of agricultural research 28: 23-31

Nguyen, M.L.; Sheath, G.W.; Smith, C.M.; Cooper, A.B. 1997. Impact of cattle treading on hill land. 2. Soil physical properties and contaminant runoff. New Zealand journal of agricultural research. In press.

Quinn, J.M.; Cooper, A.B.; Davies-Colley, R.J.; Rutherford, J.C.; Williamson, R.B. 1994. Land use effects on New Zealand hill country streams and implications for riparian management. Proceedings of the International Workshop on the Ecology and 
Management of Aquatic-Terrestrial Ecotones. University of Washington, Seattle.

Sheath, G.W.; Carlson, W.T. 1997. Impact of cattle treading on hill land. 1. Soil damage and pasture status. New Zealand journal of agricultural research. In press.
Sheath, G.W.; Hay, R.J.M.; Giles, K.H. 1987. Managing pastures for grazing animals. In Livestock feeding on pastures. Ed. A.M. Nicol. New Zealand Society of Animal Production. Occasional publication 10: 65-74. 